\title{
Are DHAs kidnapping consultants' contracts?
}

Much has been written about the vicissitudes of national medical manpower planning. But the extent to which national plans materialise as the right consultants working in the right numbers in the right hospitals depends as much on how consultants are appointed and employed as on how right any grandiose national plan might be. Certainly, the medical profession has always regarded the tradition of consultants' contracts being held by regional health authorities-teaching district consultants are an exception-as an essential safeguard for the proper deployment and employment of consultants. But not everyone in the National Health Service supports this view, as was evident at the time of the 1982 reorganisation of the service when the then Secretary of State for Social Services, Mr Patrick Jenkin, seriously considered transferring consultants' contracts from regional to district health authorities.' Such a move would have made all district health authorities the formal employers of consultants. In the event, $\mathrm{Mr}$ Jenkin, who was lobbied vigorously by many interested parties, including the BMA, decided to maintain the status quo. So regional health authorities continued to hold the contracts of consultants working in non-teaching districts and teaching districts continued to hold the contracts for their own consultants.

Pressure to change this long established system had come from many non-medical sources. Some advocates believed that a change would strengthen the non-clinical disciplinary control of consultant medical staff despite the lack of any evidence of differing employment practices between teaching and non-teaching authorities before 1982. Others believed that it would improve a district's ability to take managerial decisions about clinical workload and working relationships between consultants and between consultants and other staff, again without any clear evidence that such initiatives were hindered because the regional authority was the legal employer. Most of these arguments, however, were subordinated to the principal claim that as employing authorities in their own right, with statutory obligations to provide patient services, the district health authorities ought to have the right to employ consultant medical staff.

\section{Many arguments against transferring controls}

The arguments against such a transfer of responsibility were many. Doctors feared that local pressures-including political pressures-might militate against the appointment of professionally appropriate candidates. They also perceived a threat to their clinica freedom because the employer was "too close" to the consultant. Other arguments were based on practical considerations such as the small average size of the new district health authorities and the contractual difficulties resulting from consultants working in several adjacent districts. If, however, there was any fear in the medical profession that consultants would suffer from too tight a managerial and disciplinary constraint as an employee it rarely surfaced in the public debate at the time.

Department of Adult Education, University of Keele, Keele

ROGER DYSON, BA, PHD, director
When most consultants' contracts remained at region the BMA breathed a sigh of relief, and everyone believed that the issue had been resolved for some time to come. Alas, the events of the past 12 months or so have proved that the pressures for change persist and also that the debate in 1981-2 was misplaced in focusing on the issue of who should hold a consultant's contract. Much of what the "reformers" wanted to achieve in 1982 has now been achieved by other means, and much of what the medical lobby sought to protect has been lost, without challenging the argument that districts were on the whole too small to be employers of their own consultant medical staff.

Traditionally, and for the first year or two after 1982, consultants were appointed by regional health authorities and in some cases appointments were influenced by nationally imposed constraints. When a district wished to have a straightforward replacement appointment that was usually not too difficult. If, however, a district wanted to change the specialist nature of a post after a consultant had retired that was more difficult. Indeed, it could well prove impossible if regional or national policy constraints forbade the change. In any case, decisions on new consultant appointments were taken exclusively by the regional health authority, as were-and still are-decisions on consultant appointments in regional based specialties.

\section{Two ways for new appointments}

This right of the regional health authority operated in two different ways. In one the district authority, its medical advisory committee, or both would argue for a new appointment in a particular specialty, hoping to lobby the regional health authority until it created the post. In the other procedure the region initiated the offer of a new consultant post to a district-an offer that could be unexpected and which neither the district authority nor the local consultant medical staff had necessarily requested. An authority offered such an unexpected consultant post would usually accept it on the grounds that money came with the consultant and that to refuse would be politically unwise.

This latter procedure clearly illustrates the two essential ingredients of the traditional system. The region exercised its ability to say no and the decision to earmark-or to top slice as the procedure is called-the regional revenue allocation for new consultant appointments meant that districts perceived new appointments as acts of God that were not directly revenue related. So long as these procedures persisted the regional medical officer was the principal initiator of new consultant appointments, and he in turn was backed by a structure of regional advisory committees drawn from senior members of the profession in the region. Even when a district health authority made its own recommendations for new consultant appointments these were vetted by senior consultants in the regional advisory committee machinery. This ensured that effective control of the pace of new appointments, the location of new appointments, and the specialty order of new appointments was for practical purposes in the hands of senior medical staff

Understandably, such a system of virtual professional self control has been attractive to doctors, and it could be that the desire not to upset this system influenced the debate to retain consultants' contracts at region. What has been described here as the traditional system of consultant appointments opens up some interesting avenues for debate that are not the central concern of this paper. For 
example, if districts always accepted new posts because they did not see them as directly revenue related it could be argued that the limit on the expansion in consultant posts after the Short report ${ }^{2}$ was influenced principally by the most senior members of the profession within the regions rather than by authorities or their administrators.

\section{Dramatic effects of change}

To return to my main theme, the change in the traditional system has not been uniform across the country but where it has been complete the effects have been dramatic. National and regional controls on consultant appointments have now been largely released (in part in response to pressure from the profession) and at the same time regions have ceased to top slice for consultant appointments and have required districts to fund the full revenue consequences themselves. Suddenly districts can have any consultants they wish provided that they pay for them out of their own money. This simple change in the rules, where it has occurred, has created a new and important role for the district health authority and extended the influence and authority of the newly appointed district general managers.

District health authorities believe that they have a clear perception of the priority health needs of their districts and now that they have to vote their own money to meet the revenue consequences of consultant appointments they expect to determine the priority order of those appointments. Furthermore, the decision to leave the initiation of new consultant appointments primarily with the districts has raised the question of value for money. If a new surgeon or anaesthetist is appointed the question of how many theatre sessions the district can afford or obtain extra funds for becomes a matter of debate for the district health authority rather than the exclusive subject of exchanges between the regional medical officer, the district medical officer, and the college or faculty adviser. As things stand it will not be long before faculty advisers on consultant appointments will be marshalling their arguments consciously for district general managers and district health authority. members with the knowledge that new consultant appointments will often hinge on the debate about appropriate workloads.

In regions where these changes have been more full blooded the principal control over the pattern of consultant medical appointments has been transferred away from regional health authorities and regional medical officers and their medical advisory committee structures towards district health authorities and their medical advisory machinery. Under this system the majority of new consultant posts will be created in the RAWP gaining districts, they will be determined by locally perceived needs, and any appointments will be less influenced than in the past by such matters as the balance of specialties across a region. The change will not stop here. It will increasingly mean districts entering into direct debates with faculty and college advisers on issues of workload, with district health authorities having the right to reject new appointments whenever they judge the professional view on workload to be too prescriptive or unhelpful.

This analysis may be extended from new posts to the filling of vacant ones. If top slicing has ceased districts will wish to take their own decisions about replacements. Members will be influenced by their views on the district's service priorities and its workload. Such local freedom implies greater potential movement up and down for individual medical specialties and will create dilemmas for colleges seeking to increase the number of consultant posts while wishing to retain tight control of workload. Taken together, the events of the past two years have meant a great reduction in the influence and authority of the medical advisory machinery that backs the regional medical officers. I believe that these were some of the issues at stake in the "who holds the contract" debate of 1981. The outcome is hard to predict but the analysis suggests that at least one firm conclusion can be made. Where regions have ended the practice of top slicing for consultant appointments and where regions have become generous in their formal approval for new consultant appointments that are fully funded out of district revenue the effective control of the pattern of senior medical appointments inevitably passes to the district health authority. This change means that the influence and importance of regional medical advisory committee machinery will decline and the interest taken by district health authorities in the detailed workload of individual consultants will increase.

So the answer to the question "Are district health authorities kidnapping consultants' contacts" must be a qualified Yes. Qualified because not all regions have proceeded in this direction at the same pace. Nationally, however, the direction of change is clear. Finally, I have not presumed to comment on the value or otherwise of these changes. I have merely noted the shift in the balance of responsibilities between region and district and pointed out the implications that this will have for the future debate about the workloads of consultants. No doubt doctors will pick up the debate from here.

\section{References}

1 Anonymous. Most consultants' contracts to stay with RHAs. BrMed J 1981;283:1141 2 Social Services Committee. Fourth report. Medical education with special reference to the number of doctors and the career structure in hospitals. London: HMSO, 1981. (Short report.)

\section{"NHS Handbook" from NAHA “Progress in partnership"}

In its revised form the NHS Handbook from the National Association of Health Authorities in England and Wales provides a comprehensive guide to all aspects of the National Health Service. The handbook was first published in 1980 and the new edition incorporates the many changes that have taken place in the NHS since that date. It is divided into five sections: structure and management; finance and information; planning; health care services; and pesonnel. There are chapters on the role of the health authority member, family practitioner services, community health councils, care in the community, competitive tendering, voluntary services and the NHS, and industrial relations at national level.

The handbook is available from the NAHA Garth House, 47 Edgbaston Park Road, Birmingham B15 2RS, price $£ 12$.

1 National Association of Health Authorities in England and Wales. NHS handbook. Birmingham: NAHA, 1985.
Ways of improving collaboration between health and local authorities in planning and delivering health care and social services have been recommended in a report Progress in Partnership published by the Department of Health. The report was produced by a working group set up by the Association of Metropolitan Authorities, the Association of County Councils, the London Boroughs Association, the Association of District Councils, the National Association of Health Authorities, and the DHSS.

The recommendations concentrate on four requirements. There is a need to define the joint planning task. Joint planning should aim to generate joint strategic plans and short term programmes for each client group. There is a need to generate a greater momentum in joint planning, a need for practical, workable structures to enable joint planning to take place, and a need for a more radical approach to the use of resources.

\section{Compensation for dispensing doctors' "dead stock" on scheduled list}

In September the General Medical Services Committee asked local medical committees whether a compensation scheme should be negotiated to cover dispensing doctors' "dead stock" (28 September, $\mathrm{p}$ 915). When the limited list was introduced on 1 April it was agreed that dispensing doctors could continue to supply National Health Service patients with drugs on the scheduled list if the patient paid for them. The GMSC believes that a realistic assessment could now be made of the amount of stock that has not been prescribed or cannot be returned to suppliers. The committee would like to receive the views of those local medical committees who have not so far commented on whether a compensation scheme should be negotiated. Comments are requested by 31 December. 